\title{
Medical school education at the turning point?
}

\author{
Markus Müller
}

Published online: 23 February 2018

(C) Springer-Verlag GmbH Austria, part of Springer Nature 2018

\section{Dear Colleagues,}

We are all witnesses to drastic changes in healthcare and education systems. Our universities, hospitals and education systems are in a sharp international competition for creation of value and best minds, a competition that also causes discomfort.

In German-speaking countries, headlines are currently omnipresent on "regional shortages of physicians" and demands for reform of medical school admission and medical education. The slogan "universitas semper reformanda" is not new. Relatively new, however, is the unmistakable call for more rapidly deployable university graduates of the globally mobile generation $Y$ for specific geographic regions. The structure and processes of the current healthcare systems are usually taken for granted; powerful trends such as urbanization, globalization and migration are often neglected like the fact that the number of physicians in German-speaking countries has risen steadily over the past 30 years and has more than doubled in Austria.

The criticism of medical education is often overlapped by another question: the legitimacy of classical academic medical education at all. Historically, this debate has already been negotiated several times, as for instance in the nineteenth century. In the wake of the national cabinet wars of the 18th and 19th century, research-free academies for wound and military doctors were founded, such as in Vienna in 1785 the Josephinum. According to the director of this

Keynote address at the annual meeting of the Bavarian Chamber of Physicians 2017.

M. Müller, M.D. $(\bowtie)$

Medical University of Vienna, Spitalgasse 23, 1090 Vienna, Austria

markus.mueller@meduniwien.ac.at
Josephs Academy, “... the doctors graduated from the $\mathrm{K} \& \mathrm{~K}$ universities ... would have little desire to devote themselves to field medical services, most field doctors were born foreigners ... and perform better (1843)". After several phases of opening and closing, however, the Josephinum, similar to other European academies, was closed in 1874 .

Today academic education is today no longer simply a process of individual maturation but according to Austrian philosopher Konrad Paul Liessmann perceived as an "economic happiness and success promise" of a knowledge society. Actually, a paradox because the raw material "knowledge", the protected capital of academic guilds was democratized by the digital revolution and thus economically devalued. Everyone has access to every form of knowledge today at all times. The sentence of a patient "Doctor I think I have Hashimoto disease" says a lot about medicine of the present. In connection with a decreasing "return on investment" and of an increasing number of diplomas today the term "education bubble" seems appropriate.

So why are there really universities? The Swiss molecular biologist Gottfried Schatz emphasized in his ceremonial lecture on the 650th anniversary of the University of Vienna that the word "knowledge" does not appear in the University foundation charter. The goal of the foundation is "... to increase the common good, reason and modesty and ... to make every wise person more reasonable and bring an unwise person to human reason." If one accepts this idea, academic teaching is not primarily about knowledge transfer, which often can also carry a know-it-all-better character, but to the training of a lifelong attitude. An attitude of intellectual restraint and solitude, also based on the Socratic principle. The actual business of the universities is therefore not to "know" but to wrestle with the "non-knowledge" (on an individ- 
ual level of today called Life Long Learning) or to transform "not-yet-knowledge" into "knowledge".

This idea was often in contrast to the allegedly securely positioned "Zeitgeist". It is free, transnational, apolitical, individualistic, critical, committed to plurality and aims at an enlightened and free image of man. This attitude, a cultural achievement comparable to that of music or art, has also borne fruit for countless generations of patients through the development of scientific methodology in medicine. Konrad Paul Liessmann currently sees the benefit of an academic attitude in the construction of a "sensitivity to lies, exaggerations, hype, phrases and platitudes of the present". In medicine too, the primacy of the doctrine, the "narrative", of pharmaceutical marketing strategies or of independent critical analysis is hidden here.

All universities are still facing classical questions for their future strategy today:

- To which educational goal do we want to train?

- To a goal of today or tomorrow?

- Do we currently need more or less scientific academic education?

In this context I would like to address these challenges by 4 theses:

Thesis 1 The practice of medicine will change substantially. Just as we smile today about the understanding gastric ulcer pathogenesis 30 years ago, today's textbooks will soon be obsolete. Diagnoses and therapies will change with "omics" technologies and the trend to personalization. Digitalization and its fast-growing offspring "Artificial Intelligence" and "Machine Learning" will also revolutionize routine care and replace manpower and expertise. In view of the rapid progress of automated image recognition, the question arises of the future of classical radiology. Currently, android robots are being tested at our hospital. In the USA, a telemedicine "hospital without patients" has just been opened for high-tech care close to home. The introduction of IT and sensor technologies will lead to a renaissance of preventive medicine over repair medicine, not least due to increasing cost pressure. According to an analysis by the University of Zurich, in the future patients will increasingly be provided with near-home, telemedicine and self-management systems. Doctors of the future will no longer be technicians to the present extent but empathic companions of patients in a high-tech environment. Empathy and creativity will not be replaced by machines. Orientation and attitude towards new things will become more important for young colleagues than concrete technical knowledge.
Thesis 2 Medical research and routine care will no longer run strictly separated but form a continuum. An increasing number of patients are already being treated in clinical trials. "Early access" and "adaptive approval”, i.e. gradual approval processes as already suggested by the European regulatory authority, will become daily practice. This will require a deeper insight into the scientific foundations of diagnostics and therapy development.

Thesis 3 In medicine, many completely new jobs will emerge, leading to a broader and work-sharing concept of "healthcare workers." Other occupational groups, such as pharmacists, nurses, paramedics, and medical technicians are already aiming for a qualitatively different position in care, as cost pressure, bureaucratization, demography and urbanization will lead to an "upwards" qualification spiral. Universally trained physicians will no longer be used as writing and administrative staff, nursing staff or technicians. A cross-disciplinary specialization pyramid and a highly differentiated training system will emerge.

Thesis 4 In the future, a more differentiated offer for "healthcare workers" will be needed. The success of science-oriented medicine is already leading to a significant increase in the number of new universities and training establishments, especially in Asia. Training institutions will be more differentiated. At the top of the pyramid will be research universities that are able to offer modern scientific curricula and at the base will be research-free institutions. Doctors will only be trained at strong, future-oriented locations at research universities. The future model of education will be focused on "tomorrow": modern management theories speak of a T-shape education (broad, flexible academic basis with contemporary specialization) compared to one focused on today I-shape (specialized training without basis). In this sense, the present trend to conduct research-free medical education as a business model (in the US "offshore medical schools" in the Caribbean) or science-distant/sciencefree "Dr. med. light" training in Europe, represent a wrong path.

Theses 1-4 are, in my opinion, crucial for the future of academic medical education and for the quality of the position of Europe, the cradle of the university institution. In a global competition, we must focus on more and not less scientifically oriented content, i.e. T-shape and the ability to deal with convergence issues; however, university medicine cannot solve all the problems of inefficient healthcare systems, demography and urbanization. In Austria there is a considerable need for catching up. In the Organisation for Economic Co-operation and Development (OECD), the attractiveness of a location for workers is 
an important indicator. On average, $17 \%$ of foreigntrained doctors work in the OECD, 35\% in Switzerland and $4 \%$ in Austria.

I close with a quote from Nobel Laureate Eric Kandel whose life achievement was to give the process of education a neurobiological basis that also reminds us of the formative influence of schools and universities. "We are who we are because of what we learn and what we remember"

Conflict of interest M. Müller declares that he has no competing interests. 